\title{
Dissociation of Automatic and Strategic Lexical-Semantics: Functional Magnetic Resonance Imaging Evidence for Differing Roles of Multiple Frontotemporal Regions
}

\author{
Brian T. Gold, ${ }^{1}$ David A. Balota, ${ }^{4}$ Sara J. Jones, ${ }^{1}$ David K. Powell, ${ }^{3}$ Charles D. Smith, ${ }^{1,2}$ and Anders H. Andersen ${ }^{1,3}$ \\ ${ }^{1}$ Department of Anatomy and Neurobiology, ${ }^{2}$ Department of Neurology, and ${ }^{3}$ Magnetic Resonance and Spectroscopy Center, Chandler Medical Center, \\ University of Kentucky, Lexington, Kentucky 40536-0298, and ${ }^{4}$ Department of Psychology, Washington University, St. Louis, Missouri 63130
}

\begin{abstract}
Behavioral research has demonstrated three major components of the lexical-semantic processing system: automatic activation of semantic representations, strategic retrieval of semantic representations, and inhibition of competitors. However, these component processes are inherently conflated in explicit lexical-semantic decision tasks typically used in functional magnetic resonance imaging (fMRI) research. Here, we combine the logic of behavioral priming studies and the neurophysiological phenomenon of fMRI priming to dissociate the neural bases of automatic and strategic lexical-semantic processes across a series of three studies. A single lexical decision task was used in all studies, with stimulus onset asynchrony or linguistic relationship between prime and target being manipulated. Study 1 demonstrated automatic semantic priming in the left mid-fusiform gyrus (mid-FFG) and strategic semantic priming in five regions: left middle temporal gyrus (MTG), bilateral anterior cingulate, anterior left inferior prefrontal cortex (aLIPC), and posterior LIPC (pLIPC). These priming effects were explored in more detail in two subsequent studies. Study 2 replicated the automatic priming effect in mid-FFG and demonstrated that automatic priming in this region is preferential for the semantic domain. Study 3 demonstrated a neural dissociation in regions contributing to the strategic semantic priming effect. Strategic semantic facilitation was observed in the aLIPC and MTG, whereas strategic semantic inhibition was observed in the pLIPC and anterior cingulate. These studies provide reproducible evidence for a neural dissociation between three well established components of the lexical-semantic processing system.
\end{abstract}

Key words: language; fMRI; lexical; semantics; word recognition; priming

\section{Introduction}

Neuropsychological and functional neuroimaging studies have demonstrated the involvement of a network of frontotemporal brain regions in lexical-semantic processing (for review, see Bookheimer, 2002). However, establishing the cognitive roles of regions within this network has proven difficult. Psycholinguistic priming studies have demonstrated three qualitatively different cognitive components of the lexical-semantic system: automatic activation of semantic representations, strategic retrieval of semantic representations, and inhibition of competitors (cf. Neely, 1977). Semantic priming refers to the phenomenon that people are faster in responding to a target when it is preceded by a semantic prime than an unrelated word. Semantic priming at short stimulus onset asynchrony (SOA) is dominated by automatic processes because insufficient time is available for strategy development. Strategic semantic priming mechanisms take longer to

Received Feb. 22, 2006; revised April 16, 2006; accepted May 8, 2006.

This work was supported by National Institutes of Health (NIH) Grant R03 DC007315 (B.T.G.) and a pilot grant as part of NIH Grant P50 AG05144-21 (B.T.G.). We thank Drs. Randy McIntosh and Michael Beauchamp and two anonymous reviewers for helpful discussions.

Correspondence should be addressed to Dr. Brian T. Gold, Department of Anatomy and Neurobiology, University of Kentucky School of Medicine, Lexington, KY 40536-0298. E-mail: brian.gold@uky.edu.

DOI:10.1523/JNEUROSCI.0808-06.2006

Copyright $\odot 2006$ Society for Neuroscience $\quad$ 0270-6474/06/266523-10\$15.00/0 develop, include both facilitation and inhibition components, and draw on conscious strategies (cf. Balota et al., 1992).

Some semantic priming studies with neurological patient groups have suggested a posterior-anterior division of labor between automatic and strategic lexical-semantic processes, linking automatic priming with left temporoparietal regions and strategic priming with left frontal regions. For example, reduced semantic priming at short SOA has been reported in patients with lesions of the left temporoparietal cortex (Milberg et al., 1995). Conversely, reduced priming at long SOA has been reported in patients with lesions of the left frontal cortex (Milberg and Blumstein, 1981; Hagoort, 1993). The results are important but limited in anatomical specificity.

By taking advantage of the high spatial resolution afforded by functional neuroimaging, it may be possible to differentiate the neural bases of automatic and strategic lexical-semantic processes with finer precision. However, most relevant studies have used explicit semantic tasks that conflate automatic and strategic semantics (MacLeod, 1991). More recently, functional neuroimaging studies have begun to incorporate linguistic priming paradigms. Through the use of a common task and direct manipulation of the linguistic relationship between prime and target and/or SOA, these studies offer the potential of a more sensitive window into the neural architecture of component lexicalsemantic processes. In general, these studies have demonstrated 
that some brain regions previously implicated in semantic processing show decreased hemodynamic response associated with behavioral semantic priming (Mummery et al., 1999b; Rissman et al., 2003). Such neuroimaging decreases associated with linguistic priming may reflect more efficient neural processing, in a manner similar to decreases associated with repetition priming (for review, see Wiggs and Martin, 1998).

Of particular relevance, Rossell et al. (2003) compared automatic and strategic lexical-semantic processes using a priming paradigm in which related and unrelated trials were intermixed within separate short and long SOA runs. Greater priming at long SOA was observed in the right parietal cortex, with no regions showing greater priming at short SOA. It is therefore possible that automatic and strategic lexical-semantic processes are subserved by an undifferentiated frontotemporal network. Another possibility is that some frontotemporal regions do contribute preferentially to automatic and strategic lexical-semantics on a trial-bytrial basis and that such preferentiality may be revealed when short and long SOA trials are intermixed within the same runs.

\section{Materials and Methods}

To explore this question, we conducted three large, rapid event-related functional magnetic resonance imaging (fMRI) studies of linguistic priming. In each study, a single visual lexical decision task was used, with the linguistic relationship between prime and target and/or the SOA being manipulated. Methods common to all studies are reported first, followed by a description of each study.

Subjects. Seventy-two subjects between the ages of 18 and 35 participated. All subjects provided written informed consent in a manner approved by the University of Kentucky Institutional Review Board and were paid for participating. Twenty-four subjects participated in each study (study 1: 13 females and 11 males; mean age, 23.8 years; SD, 5.4; study 2: 14 females and 10 males; mean age, 22.9 years; SD, 3.7; study 3 : 13 females and 11 males; mean age, 23.6; SD, 4.1). All participants were right-handed, native English speakers who reported no neurological disease and had normal or corrected-to-normal visual acuity.

Behavioral procedures. All studies involved a primed visual lexical decision task. Participants were informed that pairs of letter strings would be presented and were instructed to decide if the second, underlined letter string was a word or a nonword. Most semantic pairs shared an associative relationship (e.g., SAND-BEACH), whereas others shared both associative and categorical relationships (e.g., SPOON-FORK). Stimulus presentation and recording of responses was implemented with E-Prime software (Psychology Software Tools, Pittsburgh, PA), using an MRI-compatible projection system (SilentVision SV-6011 LCD; Avotec, Stuart, FL). Visual stimuli (42-point Courier uppercase font) were projected onto a screen at the back of the magnet bore and viewed by subjects through a mirror mounted on the MR head coil. Responses were made via button presses, using a fiber-optic button-box that registers latencies to the nearest millisecond. No stimulus was repeated within a subject to avoid repetition priming. Reaction times (RTs) were measured from the onset of target display. Behavioral RTs were computed for correct trials of each condition. Each participant's median RT for correct trials was entered into statistical analyses to minimize the effect of outliers.

Study 1: Are automatic and strategic lexical-semantics dissociable at the neural level? The design consisted of a primed lexical decision task with pairs presented visually at short and long SOA. A schematic is shown in Figure 1. SOAs of $250 \mathrm{~ms}$ (short) and $1000 \mathrm{~ms}$ (long) were used, representing frequently studied intervals in the behavioral literature (Neely, 1991). Targets were present for $1300 \mathrm{~ms}$ and were underlined to aid identification. A brief intertrial interval (ITI) consisting of visual fixation was used to minimize the possibility of cross-trial priming (Neely et al., 1989). The visual fixation consisted of a series of letters (XXXXX), matched to the mean prime length (five letters), serving to equate roughly the visual angle and duration of letter exposure across SOA conditions. The design matched approximately the perceptual compo-

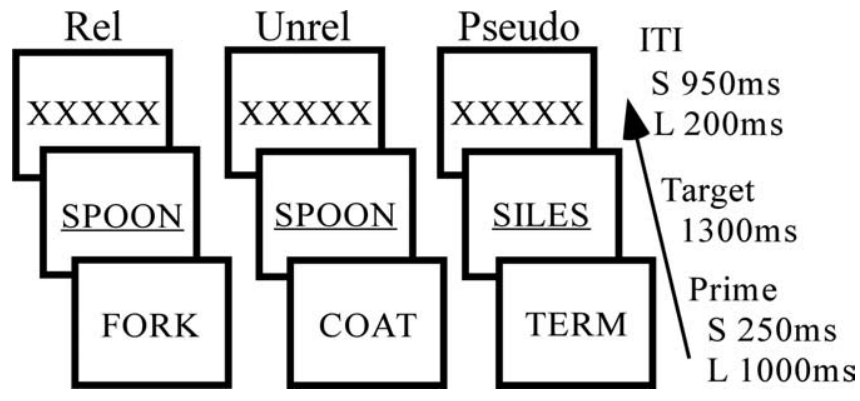

Figure 1. Study 1 priming paradigm. The trial length was $2500 \mathrm{~ms}$. The sequence of events was identical across short and long SOA trial types, differing only in timing. The prime was present for $250 \mathrm{~ms}$ during short trials (S) and $1000 \mathrm{~ms}$ during long trials (L). Primes were followed by a related (Rel), unrelated (Unrel), or pseudoword (Pseudo) target. Targets were followed by an ITI consisting of a series of letters, warning participants of the next trial.

nents of letter processing, lexical decision, and the motor response output across SOA conditions.

A total of 240 semantically related prime-target word pairs (e.g., SPOON-FORK) were selected from a larger corpus producing robust priming effects in previous research (Balota et al., 1998). Related pairs were divided into shorter lists for counterbalancing and matched for frequency and length. Lists of unrelated pairs were generated from the related-pair lists by pseudorandomly re-pairing targets and primes, with the constraint that the new pair did not share a linguistic (orthographic, phonological, or semantic) relationship. Presentation of the related and unrelated versions of lists were then rotated across subjects such that primes and targets appeared an equal number of times as part of related and unrelated pairs, in each SOA condition, ensuring that priming effects would be attributable to the relationship between prime-target pairs as opposed to other stimulus differences. An equal number of pseudoword trials were included to promote the lexical decision task. Pseudoword targets were constructed by changing one letter of a group of word stimuli (not used in the present experiment) to encourage semantic processes in discriminating words from nonwords. Pseudoword targets were matched with word targets for length. Word primes used in the pseudoword target trials were matched for frequency and length with primes used in word target trials.

The experiment consisted of three prime-target trial types (related, unrelated, and pseudoword) at each SOA. In addition, visual fixation trials $(+)$ were included to create a baseline condition for analyses and promote stimulus jittering. Participants completed a total of 720 trials in the experiment, divided into 180 trials in each of four runs. Each run was divided equally among 60 word target (15 for each of the four types), pseudoword target, and fixation (+) trials. Thus, participants completed a total of 60 trials in each of the four word target conditions (shortrelated, short-unrelated, long-related, and long-unrelated).

Study 2: exploring the degree of domain preferentiality and generalizability of automatic lexical-semantic processing in mid-fusiform gyrus. Results from study 1 suggested a role for mid-fusiform gyrus (mid-FFG) in automatic lexical-semantics. An important question arising from this finding is whether the mid-FFG is preferential for semantic processes. Human lesion studies have demonstrated a role for the left posterior FFG in processing the visual form (orthographic structure) of language symbols (Dejerine, 1892; Damasio and Damasio, 1983). Recent fMRI results have confirmed a role for a portion of the left posterior FFG (peak Talairach $x$, $y, z$ coordinates: $-43,-54,-12)$ in orthographic processing, demonstrating that this region showed a greater response to letter strings than non-letter shapes, regardless of case or font (Cohen et al., 2000, 2002). In study 1 , peak automatic semantic priming was observed in a portion of mid-FFG $(-40,-43,-15)$ anterior to the coordinates reported by Cohen et al. (2002). Still, the location of the priming effect within the ventral visual stream, bordering regions implicated in orthographic analysis, raises the question of whether automatic lexical-semantic processes emerge from the same structures supporting automatic orthographic processes or are guided by distinct structures. That is, do structures 


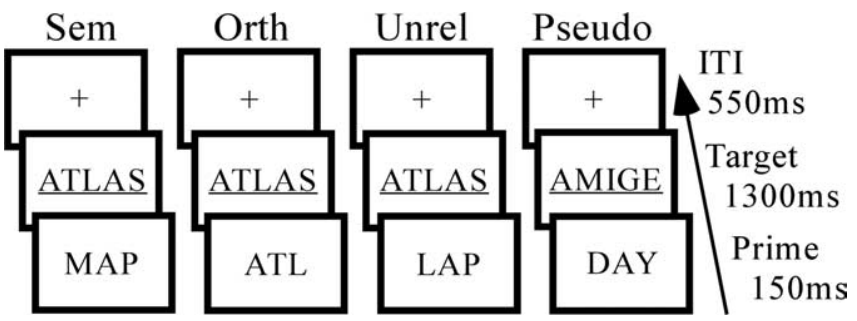

Figure 2. Study 2 priming paradigm. The trial length was $2000 \mathrm{~ms}$. The prime was present for $150 \mathrm{~ms}$ and was followed by a semantically related (Sem), orthographically related (0rth), unrelated (Unrel), or pseudoword (Pseudo) target. Targets were followed by an ITI consisting of visual fixation $(+)$.

associated with automatic orthographic processing of language symbols contribute the basic representational building blocks that guide automatic visual semantics, or do automatic visual semantics draw on a distinct, more anterior patch of the inferior temporal cortex?

A second question arising from the results of study 1 is whether the automatic semantic priming effect observed in mid-FFG is idosyncratic to one specific short SOA interval or plays a more general role in automatic lexical-semantics. In study 2, we explored these two issues by comparing blood oxygenation level-dependent (BOLD) signal decreases associated with lexical decisions preceded by semantic and orthographic primes at an SOA interval $(150 \mathrm{~ms})$ slightly shorter than the one used in study $1(250 \mathrm{~ms})$, but still emphasizing automatic processing. A schematic is shown in Figure 2.

Behavioral research has demonstrated that certain prime-target characteristics are required to produce orthographic priming. First, when the prime is visible (e.g., unmasked with an $\sim 60 \mathrm{~ms}$ prime duration or more), orthographic priming is observed with partial-word primes (hideou-hideout) (Mewhort and Beal, 1977; Jordan, 1986), but not word primes (hideous-hideout), presumably because the visually similar word prime competes directly with the word target at the lexical level, whereas the nonword prime does so only indirectly (Colombo, 1986; Rastle et al., 2000). Second, orthographic priming is stronger when partial-word primes share the initial letters of the target than the final letters (Mewhort and Beal, 1977; Inhoff and Tousman, 1990). Finally, orthographic priming depends critically on the orthographic neighborhood characteristics of targets. Targets with low-density neighborhoods are required to produce orthographic priming, presumably because they have less competition from neighbors than targets from high-density neighborhoods (Forster et al., 1987; Hinton et al., 1998). These behavioral findings were considered in developing prime-target pairs for the present fMRI experiment.

A large number of potential target words without orthographic neighbors ( 799 words of $n=0$ ) were initially selected from Balota et al. (2002) to generate a final set of targets that could be paired with orthographic, semantic, and unrelated primes, to allow counterbalancing of targets across different conditions. A final group of 240 targets without orthographic neighbors $(n=0)$ were selected on the basis of having a corresponding semantic prime (1) of at least 0.20 associative strength in the norms of Nelson et al. (1998) that was (2) shorter than its target (to match orthographic prime length). Orthographic primes were created by removing the final one to two letters of targets. One-half of the unrelated primes were words (like semantic primes) and one-half of the unrelated primes were nonwords (like orthographic primes), ensuring that targets could not be predicted on the basis of primes. Unrelated primes never shared the first letter with targets, or more than any one other letter, and were unrelated to targets in meaning. Orthographic, semantic, and unrelated primes were matched for length (semantic $M=4.6$; orthographic $M=4.5$; unrelated $M=4.6$; all $p>0.34$ ), and semantic and unrelated primes were matched for frequency [semantic $M=15,261$; unrelated $M=13,614$; per hundred million observations (Burgess and Livesay, $1998) ; p>0.82$ ]. The 240 prime-target pairs within each condition were then sorted into shorter condition-specific matched lists to allow counterbalancing. Presentation of lists was rotated across participants such that targets were used an equal number of times in the orthographic,

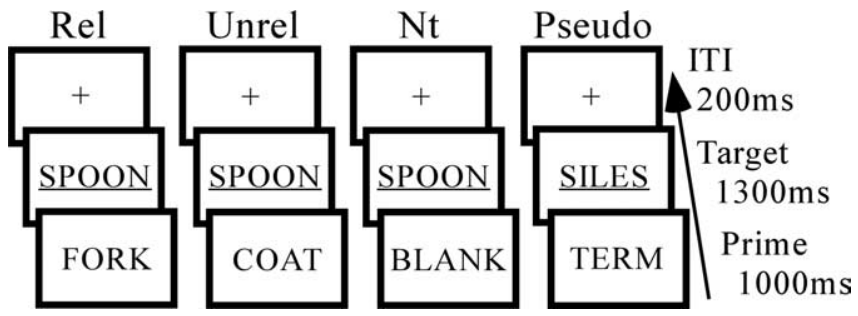

Figure 3. Study 3 priming paradigm. The trial length was $2500 \mathrm{~ms}$. The prime was present for $1000 \mathrm{~ms}$ and was followed by a related (Rel), unrelated (Unrel), neutral (Nt), or pseudoword (Pseudo) target. Targets were followed by an ITI consisting of visual fixation (+).

semantic, and unrelated conditions across different subjects. An equal number of pseudoword trials were included to promote the lexical decision task. Pseudoword targets were constructed by changing one letter of a group of word stimuli not used in the present experiment and were matched with word targets for length. As with unrelated primes, one-half of the pseudoword primes were words and one-half of the pseudoword primes were nonwords, matched for length with primes used in the three word conditions.

The experiment consisted of four prime-target trial types: semantic, orthographic, unrelated, and pseudoword. In addition, visual fixation trials $(+)$ were included to create a baseline condition for analyses and promote stimulus jittering. Participants completed a total of 720 trials in the experiment, divided into 180 trials in each of four runs. Each run was divided equally among 60 word target (20 each of semantic, orthographic, and unrelated), pseudoword target, and fixation trials. Thus, participants completed a total of 80 trials in each of the three word target conditions (semantic, orthographic, and unrelated).

Study 3: characterizing the role of brain regions in strategic components of lexical-semantics: facilitation or inhibition. Results from study 1 demonstrated a role for several regions in strategic lexical-semantics. The priming effects observed in these regions could reflect facilitated lexical retrieval or inhibition of competing lexical information. Long SOA conditions encourage expectancy strategies in which the reader is thought to generate a set of potential targets that are semantically related to the prime (Posner and Snyder, 1975; Neely, 1977; Balota et al., 1992). When the target is consistent with the expectancy set (related targets), responses will be facilitated because of reduced demands on strategic lexical search and access processes. In contrast, when targets are inconsistent with the expectancy set (unrelated targets), responses will be slowed because time is required to inhibit the expectancy set and shift attention to the presented item (Neely, 1991; Balota et al., 1992). Proper decomposition of strategic semantic facilitation and inhibition requires comparison of related and unrelated conditions to a neutral prime condition in which targets are preceded by a neutral word such "BLANK" or "READY," minimizing the expectancy strategy (Neely et al., 1989).
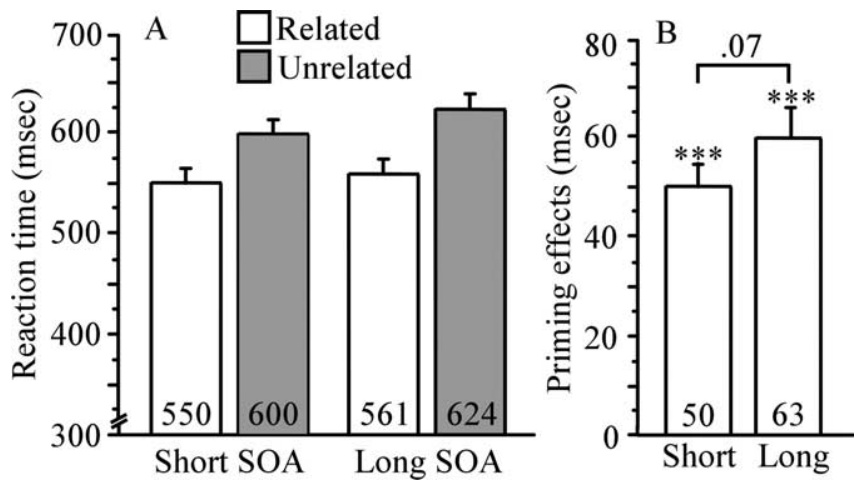

Figure 4. Study 1 RTs and priming effects. A, Mean RTs in milliseconds to targets preceded by related and unrelated primes, under short and long $S O A$ conditions. $\boldsymbol{B}$, Priming effects (unrelated - related) for short and long SOA conditions. ${ }^{* *} p<0.001$. Error bars represent SEM. Numbers within bar charts represent exact RTs and priming effects. 
Behavioral facilitation is calculated by subtracting the RT for related targets from that of neutral targets, whereas inhibition is calculated by subtracting the RT for neutral targets from that of unrelated targets. In all previous functional neuroimaging studies of primed lexical decision, including study 1 of the present research, facilitation and inhibition mechanisms have been conflated via direct comparison of unrelated and related conditions. A neutral prime condition could not be included in study 1 because of consideration of subject time in the scanner. However, in the present study using only a long SOA condition, it was possible to include a neutral prime condition. A schematic is shown in Figure 3.

Stimuli consisted of the same 240 semantically related prime-target word pairs producing robust priming in study 1 . Related pairs were divided into shorter lists for counterbalancing, matched for frequency and length. Lists of unrelated pairs were generated from the related pair lists by pseudorandomly re-pairing targets and primes, with the constraint that the new pair did not share a linguistic (orthographic, phonological, or semantic) relationship. Lists of neutral pairs were generated from the related pair lists by replacing primes with the word "BLANK." The neutral prime "BLANK" matched other primes in lexical status and mean letter length. Presentation of related, unrelated, and neutral lists were rotated across conditions such that targets appeared as part of related, unrelated, and neutral pairs an equal number of times across participants, and primes (other than the neutral prime) appeared as part of related and unrelated pairs an equal number of times across participants. An equal number of pseudoword trials were included to promote the lexical decision task. Pseudoword targets were constructed by changing one letter of a group of word stimuli not used in the present experiment and were matched with word targets for length. One-third of pseudoword targets were preceded by the word "BLANK," as was the case with word targets. The other word primes for word-pseudoword trials were matched for frequency and length with primes used in word-word pairs.

The experiment consisted of four prime-target trial types: related, unrelated, neutral, and pseudoword. In addition, visual fixation trials $(+)$ were included to create a baseline condition for analyses and promote stimulus jittering. Participants completed a total of 720 trials in the experiment, divided into 180 trials in each of four runs. Each run was divided equally among word target (20 for each of three types), pseudoword target, and fixation trials. Thus, participants completed a total of 80 trials in each of the three word target conditions (related, unrelated, and neutral).

fMRI procedures. Data were collected on a $3 \mathrm{~T}$ Siemens (Erlangen, Germany) Magnetom Trio MRI scanner. Foam padding was used to limit head motion within the coil. $\mathrm{T} 2{ }^{*}$-weighted functional images were acquired using the body coil to transmit and an eight-channel head array coil to receive. Main field $\mathrm{B}_{0}$ homogeneity was optimized at the start of each run using an automated shimming routine. Functional image runs were acquired in the transverse plane using a gradient-echo EPI sequence [echo time (TE), $30 \mathrm{~ms}$ ]. The repetition time (TR) was $2500 \mathrm{~ms}$ for

$\mathrm{C}$

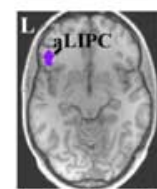

$-4535-6$

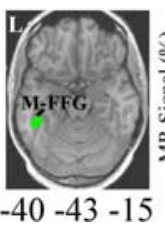

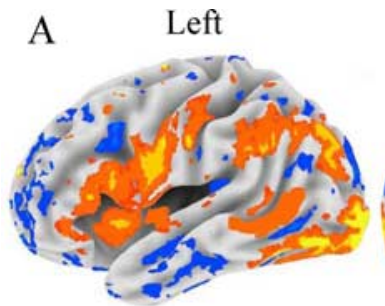
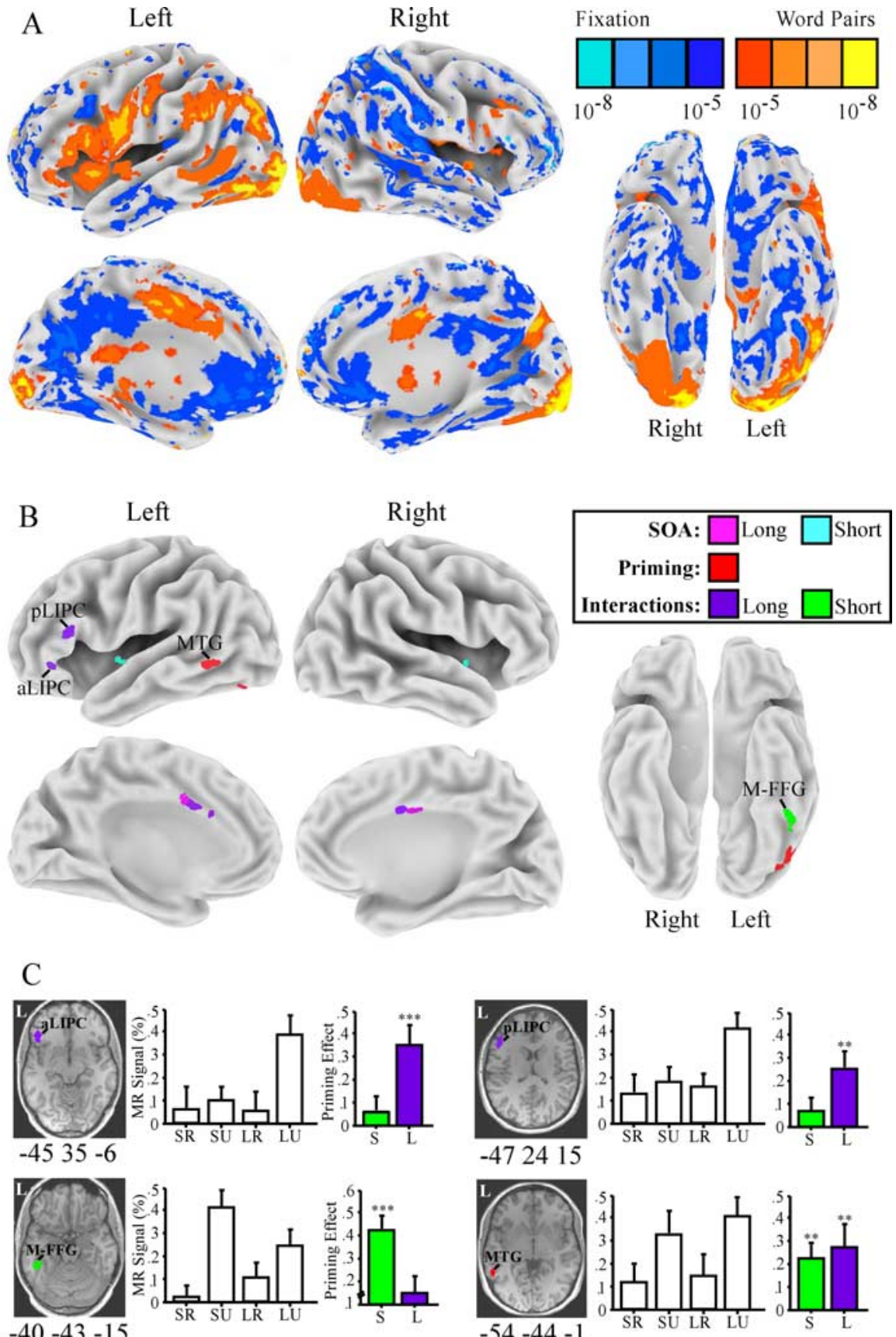

Figure 5. Study 1 MR priming effects. $\boldsymbol{A}$, Whole-brain maps comparing all word conditions with visual fixation. $\boldsymbol{B}$, Maps displaying regions activated by word pairs $(\boldsymbol{A})$ that also show an effect of $\mathrm{SOA}$, priming, or priming by $\mathrm{SOA}$ interactions. $\boldsymbol{C}$, Priming effects in one region showing priming across short and long SOA conditions (left MTG) and three regions showing priming by $\mathrm{SOA}$ interactions (aLIPC, pLIPC, and left mid-FFG). A representation of the location of each ROl is overlaid on a high-resolution image of a single subject in standardized space to promote identification on a traditional axial slice. Peak Talairach coordinates of ROls are given under structural images. Bar charts display mean MR percentage signal change from fixation for the short-related (SR), short-unrelated (SU), long-related (LR), and long-unrelated (LU) conditions. Colored bar charts show MR priming effects (unrelated - related) for short (S) and long (L) SOA conditions. ${ }^{* *} p<0.01$; ${ }^{* * *} p<0.005$. Error bars represent SEM. M-FFG, Mid-FFG. studies 1 and 3 (flip angle, $81^{\circ}$ ) and $2000 \mathrm{~ms}$ for study 2 (flip angle, $77^{\circ}$ ). Thirty-eight interleaved slices were acquired $[64 \times 64$ image matrix, $224 \times 224$ field of view (FOV), with isotropic $3.5 \mathrm{~mm}$ voxels], covering the entire cerebrum and the upper cerebellum. An event-related design was used for all studies, with runs divided between trials types of interest and fixation trials $(+)$ to create a baseline condition for analyses and promote stimulus jittering. Different trial types were ordered randomly within runs for optimal experimental efficiency (Dale, 1999). Each run began with $10 \mathrm{~s}$ of visual fixation to enable MR signal stabilization and 


\begin{tabular}{|c|c|c|c|}
\hline Region & Approximate BA & $x, y, z(\mathrm{~mm})$ & $p$ \\
\hline \multicolumn{4}{|l|}{ Priming (unrelated > related) } \\
\hline Left MTG & 21 & $-54,-44,-1$ & $<0.01$ \\
\hline Left posterior FFG & 37 & $-41,-57,-12$ & $<0.01$ \\
\hline \multicolumn{4}{|l|}{ SOA: long SOA $>$ short SOA } \\
\hline Left anterior cingulate gyrus & 24 & $-5,12,24$ & $<0.01$ \\
\hline Right anterior cingulate gyrus & 24 & $+6-428$ & $<0.01$ \\
\hline \multicolumn{4}{|l|}{ SOA: short SOA > long SOA } \\
\hline Left insula & 13 & $-42,-1,-3$ & $<0.01$ \\
\hline Right insula & 13 & $46,5,-2$ & $<0.01$ \\
\hline \multicolumn{4}{|c|}{ Interaction: greater priming at short SOA } \\
\hline Left mid-FFG & 37 & $-40,-43,-15$ & $<0.01$ \\
\hline \multicolumn{4}{|c|}{ Interaction: greater priming at long $\mathrm{SOA}$} \\
\hline Left anterior cingulate gyrus & $24 / 32$ & $-6,9,26$ & $<0.01$ \\
\hline Right anterior cingulate gyrus & $24 / 32$ & $+4,2,29$ & $<0.01$ \\
\hline $\mathrm{pLIPC}$ & $44 / 45$ & $-52,24,18$ & $<0.005$ \\
\hline aLIPC & 47 & $-47,31,-4$ & $<0.005$ \\
\hline
\end{tabular}

ended with 16-17.5 s (depending on the TR) of visual fixation to capture the hemodynamic response of the final trial. A high-resolution, threedimensional anatomic image was acquired using a time of inversion (T1)-weighted (magnetization prepared rapid gradient echo) sequence (TR, $2100 \mathrm{~ms}$; TE, $2.93 \mathrm{~ms}$; TI, $1100 \mathrm{~ms}$; flip angle, $12^{\circ}$; FOV , $224 \times 256 \times$ $192 \mathrm{~mm} ; 1 \mathrm{~mm}$ isotropic voxels; sagittal partitions) for the localization of functional activity in the stereotactic space of Talairach and Tournoux (1988).

fMRI data analysis. fMRI data were analyzed with AFNI software (Cox, 1996). A series of preprocessing steps were used to minimize artifacts. The first few functional volumes (12 s) of each run were excluded from analyses because of $\mathrm{T} 1$ saturation effects. Differences in timing between slices attributable to acquisition order were then adjusted with sinc interpolation. Next, functional images were motion corrected and registered to the image collected closest in time to the high-resolution anatomical image using a six-parameter rigid-body transformation (Cox and Jesmanowicz, 1999). Finally, functional images were smoothed spatially with a $6 \mathrm{~mm}$ full-width half-maximum Gaussian filter, and intensity was normalized to yield subsequent activation measures expressed as a percentage of signal change from baseline.

A voxel-wise multiple regression analysis was performed on each subject's preprocessed image time series to provide simultaneous parameter estimates of the hemodynamic response associated with each condition (Glover, 1999). Hemodynamic impulse response functions (IRFs) were modeled separately for each condition compared with baseline fixation by convolving correct trials with a $\gamma$-variate function (Cohen, 1997). Trials in which incorrect responses occurred were coded as a separate condition and included in the model as a nuisance covariate to increase statistical sensitivity. Additional nuisance regressors included in the model were the mean, linear trend, and movement parameters of each run estimated during image registration to remove residual variance associated with motion. Each subject's IRF data set was then transformed to the standardized space of Talairach and Tournoux (1988), using landmarks from their anatomical data sets, and resampled at $2 \mathrm{~mm}^{3}$ resolution using cubic spline interpolation.

During second-level analyses, group-based, voxel-wise ANOVAs and $t$ tests were performed on IRF data sets from the multiple regression analysis using a mixed-effect model that treated condition as a fixed effect and participants as a random effect. As a first step, the combined data from all visual word target conditions was contrasted with visual fixation. The threshold of this comparison was high $\left(p<1.0^{-5}\right)$ to compensate for the multiple comparisons produced by the large number of intracranial voxels compared. Within this distributed system involved in lexical processing, voxels were then characterized by their response to different components of lexical processing (priming relationships) at a more liberal significance threshold $(p<0.01)$ and a cluster threshold of five contig- uous voxels. A conjunction approach (Price and Friston, 1997) was used to identify common activations across levels of main effects (e.g., regions that showed consistent priming at each SOA). For example, in study 1, consistent priming effects across short and long SOAs were identified by the following: (short/unrelated - short/related) and (long/unrelated long/related). This analysis was important in identifying regions showing priming effects that generalized across SOAs [e.g., left middle temporal gyrus (MTG)]. A similar approach was used to identify regions sensitive to SOA across unrelated and related conditions. Brain activations preferential to priming at one SOA were identified from priming by SOA interactions. To ensure that effects would not result from relative deactivations, priming interactions were masked by the effect of priming specific to one SOA. For example, in study 1, regions showing preferential response to the short unrelated condition corresponded to the following: ( (short/unrelated - short/related $)>$ (long/unrelated - longrelated)), masked by (short/unrelated - short/related). Activation maps from different contrasts were projected onto a common surface using Caret software (Van Essen et al., 2001) to identify common and dissociable activation patterns across conditions.

Time course and magnitude data were extracted to estimate priming effect sizes in each condition. After identification of peak activations, region of interest (ROI) masks were generated on statistical maps comparing all word conditions versus fixation. Masks were generated using the $3 \mathrm{dcalc}$ tool in AFNI and consisted of a three-dimensional area including all voxels $(p<0.001)$ within $10 \mathrm{~mm}$ of peak activations. These ROI masks were then applied to each subject's IRF data set to extract mean time course and magnitude estimates across all voxels in an ROI during each condition. Single averaged magnitudes within ROIs were submitted to statistical tests based on a mixed-effects model, treating condition as a fixed effect and participants as a random effect.

\section{Results}

\section{Study 1 behavioral results}

Accuracy was near ceiling for the critical word trials in both short (98.1\%) and long (98.2\%) SOA conditions. The RT was computed as the mean of median RTs to correct responses to assess priming effects at short and long SOAs. Figure 4 shows mean RTs to correct responses for short and long SOA conditions and mean priming effect sizes (unrelated - related) for each SOA condition.

ANOVA indicated main effects of priming $\left(F_{(1,23)}=117.6\right.$; $p<0.0001)$ and SOA $\left(F_{(1,23)}=9.6 ; p<0.01\right)$, with slower latency at long SOAs. Planned comparisons revealed significant priming
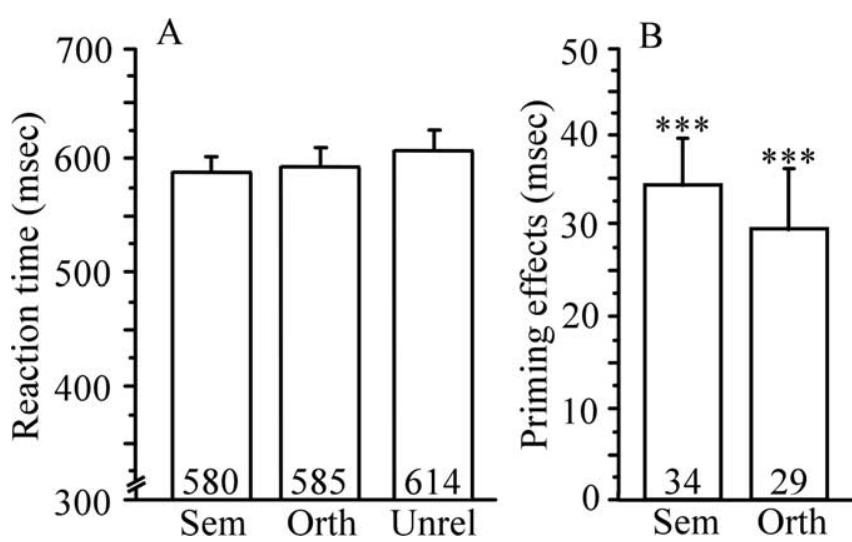

Figure 6. Study 2 RTs and priming effects. $A$, Mean RTs in milliseconds to targets preceded by semantic (Sem), orthographic (Orth), and unrelated (Unrel) primes. B, Priming effects (unrelated - related) for targets preceded by semantic and orthographic primes. ${ }^{* * *} p<0.001$. Error bars represent SEM. Numbers within bar charts represent exact RTs and priming effects. 
effects for both short and long SOA conditions $(p<0.001)$. Inaddition, there was a trend toward a priming by SOA interaction $\left(F_{(1,23)}=3.7 ; p<0.07\right)$, attributable to a larger priming effect at long SOAs. The larger priming effect at long SOA is in keeping with the finding that strategic semantic processes lead to inhibition in addition to facilitation in lexical decision (Neely, 1977; Balota et al., 1992).

\section{Dissociable neural correlates of automatic and strategic lexical-semantics}

Figure 5 summarizes the brain activation results. Comparison of all word conditions with baseline fixation (Fig. 5A) resulted in activation of a predominantly lefthemisphere network of regions, including the occipitotemporal cortex, MTG, angular and supramarginal gyri, operculum, and inferior prefrontal cortex, consistent with previous functional neuroimaging studies of lexical decision (Rumsey et al., 1997; Mummery et al., 1999b). Within this lexical processing network, a small number of these regions showed a modulated response as a function of SOA, priming, or SOA by priming interactions (Fig. $5 B$, Table 1). Greater response at long SOA than short SOA, regardless of priming, was observed in bilateral cingulate gyrus, whereas greater response at short than long SOA, regardless of priming, was observed in the bilateral insular cortex. Given that these regions showed effects of SOA but not priming, their activation pattern is likely to be associated with attentional components of SOA conditions not specific to lexical-semantics. Two regions showed consistent priming across SOA conditions: a portion of the left MTG [approximate Brodmann's area (BA) 21] and a portion of the posterior FFG ( $\sim$ BA 37/19), suggesting their role in both automatic and strategic lexical-semantics. Finally, priming by SOA interactions were observed in five regions. Greater priming at short SOA was observed in the inferior temporal cortex near the mid-FFG $(\sim \mathrm{BA} 37)$. Greater priming at long SOA was observed in the bilateral anterior cingulate gyrus $(\sim$ BA $32 / 24)$, an anterior portion of the left inferior prefrontal cortex (aLIPC; $\sim \mathrm{BA} 47$ ) and a posterior portion of the LIPC (pLIPC; $\sim$ BA 44 / 45). The regions showing priming by SOA interactions, particularly the mid-FFG (Mummery et al., 1998; Moore and Price, 1999) and LIPC (Petersen et al., 1988; Binder et al., 1997) have been activated during explicit semantic decision tasks, which likely involve both automatic and strategic semantic processes. The present results suggest fractionation of these regions as a function of automatic and strategic lexical-semantic processes.

C
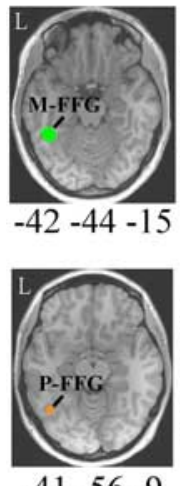
posterior FFG.
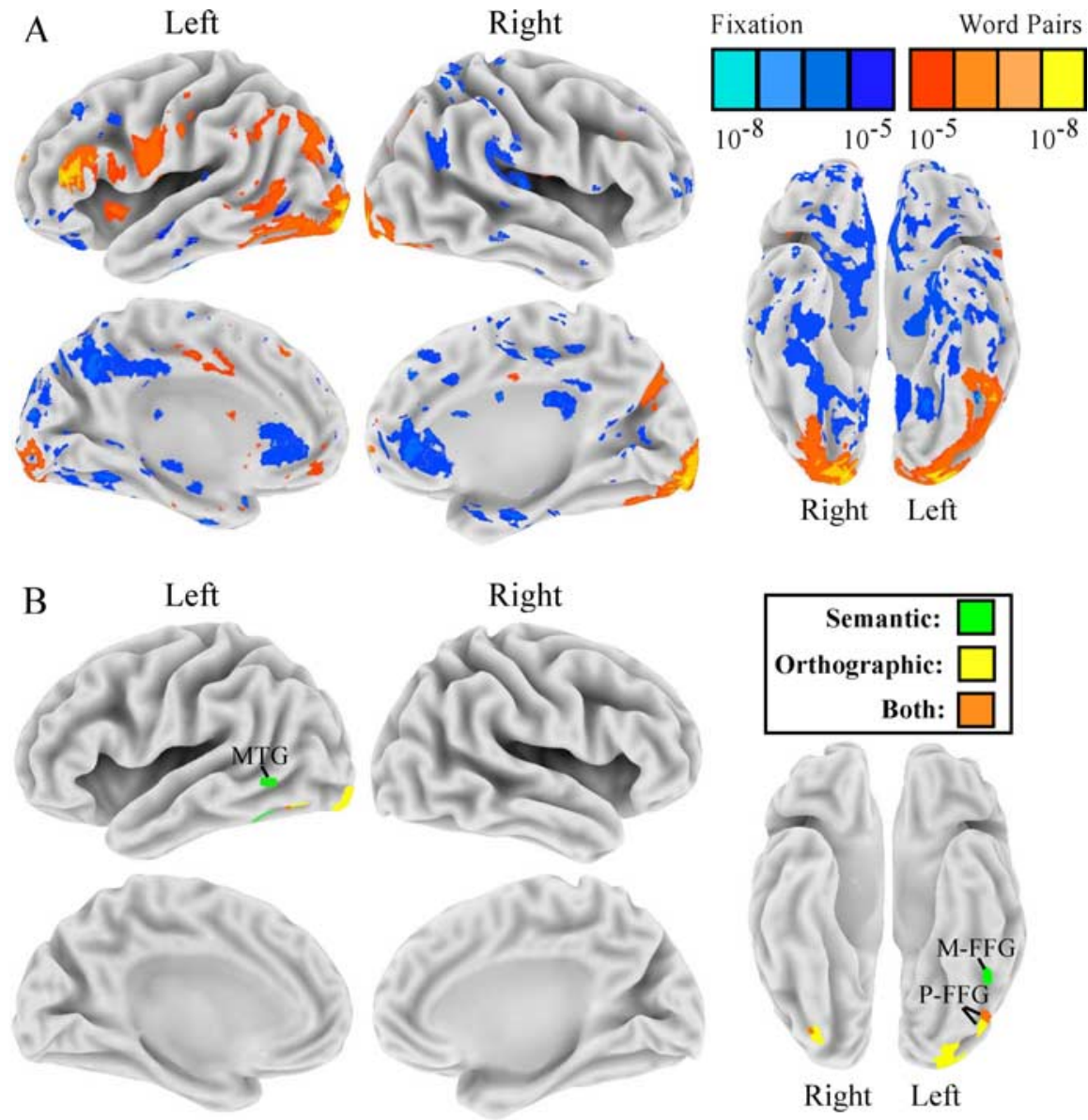

Right Left
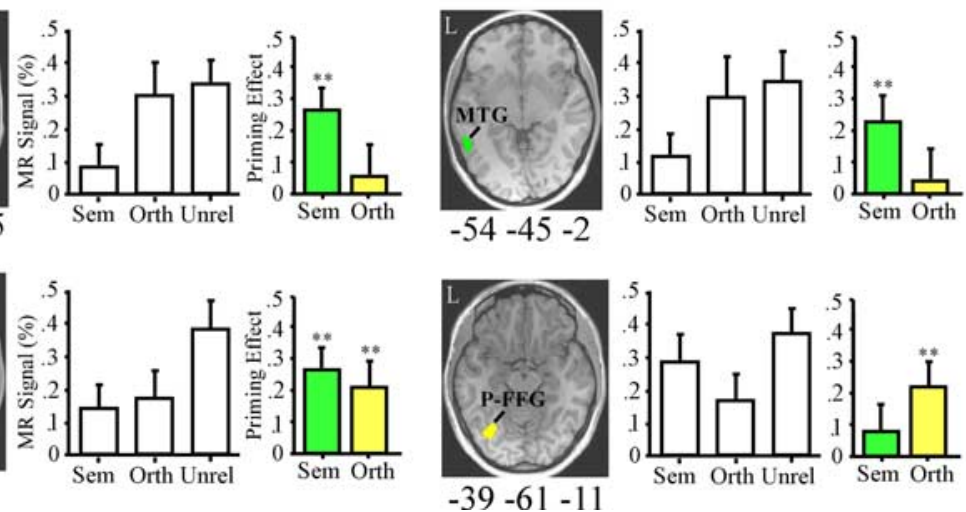

Figure 7. Study 2 MR priming effects. $\boldsymbol{A}$, Whole-brain maps comparing all word conditions with visual fixation. $\boldsymbol{B}$, Maps displaying regions activated by word pairs $(\boldsymbol{A})$ that also show consistent priming across semantic and orthographic conditions, greater semantic priming, or greater orthographic priming. $C$, Priming effects in two regions showing semantic priming (left mid-FFG and left MTG), one region showing orthographic priming (a posterior portion of the posterior FFG), and one region showing priming across both conditions (an anterior portion of the posterior FFG). Bar charts display mean MR percentage signal change from fixation for the semantic (Sem), orthographic (Orth), and unrelated (Unrel) conditions. Colored bar charts show MR priming effects for the semantic and orthographic conditions. ${ }^{* *} p<0.01$. Error bars represent SEM. M-FFG, Mid-FFG; P-FFG,

\section{Study 2 behavioral results}

Mean accuracy was near ceiling for the critical semantic $(97.3 \%)$, orthographic $(96.4 \%)$, and unrelated $(95.7 \%)$ word trials. Figure 6 shows mean RTs to correct responses for semantic and orthographic trial types and mean priming effect sizes (unrelated related) for each trial type.

ANOVA indicated a significant difference in RT to targets 


\begin{tabular}{|c|c|c|c|}
\hline Region & Approximate BA & $x, y, z(\mathrm{~mm})$ & $p$ \\
\hline \multicolumn{4}{|l|}{ Semantic and orthographic priming } \\
\hline Left posterior FFG & 37 & $-41,-56,-11$ & $<0.01$ \\
\hline \multicolumn{4}{|l|}{$\begin{array}{l}\text { Semantic priming (unrelated }> \\
\text { semantic) }\end{array}$} \\
\hline Left MTG & 21 & $-54,-45,-2$ & $<0.01$ \\
\hline Left mid-FFG & 37 & $-42,-44,-15$ & $<0.01$ \\
\hline \multicolumn{4}{|l|}{$\begin{array}{l}\text { Orthographic priming (unrelated }> \\
\text { orthographic) }\end{array}$} \\
\hline Left posterior inferior temporal & 37 & $-39,-61,-11$ & $<0.01$ \\
\hline Left extrastriate & $19 / 18$ & $-24,-71,-8$ & $<0.01$ \\
\hline
\end{tabular}

preceded by unrelated, semantic, and orthographic primes $\left(F_{(2,23)}=31.9 ; p<0.001\right)$. Planned comparisons revealed significant priming effects for both targets preceded by semantic primes $\left(t_{(23)}=7.5 ; p<0.001\right)$ and orthographic primes $\left(t_{(23)}=\right.$ $5.5 ; p<0.001)$ and no significant difference in the size of semantic and orthographic priming effects $(p=0.28)$.

\section{Automatic priming in mid-FFG is preferential for the semantic domain}

Figure 7 summarizes the brain activation results. Comparison of all word conditions and baseline fixation (Fig. 7A) resulted in activation of a predominantly left-hemisphere network of regions overlapping those of study 1 and previous lexical decision studies. Within this lexical processing network, several regions showed semantic and/or orthographic priming effects (Fig. $7 B$, Table 2). Overlapping semantic and orthographic priming was observed bilaterally in the posterior FFG ( BA 37), with the largest focus of activation in the left hemisphere. There were two major left-hemisphere foci of activation specific to orthographic priming, a region in the extrastriate cortex and a portion of the posterior FFG, similar to results reported by Devlin et al. (2004). Most importantly, there were also two major left-hemisphere foci specific to semantic priming: a region in the mid-FFG $(\sim \mathrm{BA} 37$; peak: $-42,-44,-15)$ that also showed automatic semantic priming in study 1 and a region of the lateral temporal cortex ( $\sim$ BA 21 ; peak: $-54,-45,-2)$ that showed both automatic and strategic semantic priming in study 1 . These results demonstrate that automatic linguistic priming in the mid-FFG is preferential for the semantic domain.

\section{Study 3 behavioral results}

Accuracy was near ceiling for the critical word trials in the related (98.9\%), neutral (98.2\%), and unrelated (95.1\%) conditions. Figure 8 shows mean RTs to correct responses for each condition and mean facilitation (neutral - related) and inhibition (unrelated - neutral) effect sizes.

ANOVA indicated a significant difference in RTs between the three conditions $\left(F_{(2,46)}=66.3 ; p<0.001\right)$. Planned comparisons revealed both significant facilitation $\left(t_{(23)}=8.2 ; p<0.001\right)$ and inhibition effects $\left(t_{(23)}=3.9 ; p<0.001\right)$. The effect of facilitation was significantly larger than the effect of inhibition $\left(t_{(23)}=2.4 ; p<0.05\right)$.

\section{Dissociable neural correlates of lexical-semantic facilitation and inhibition}

Figure 9 summarizes the brain activation results. Comparison of all word conditions and baseline fixation (Fig. 9A) resulted in activation of a predominantly left-hemisphere network of re-
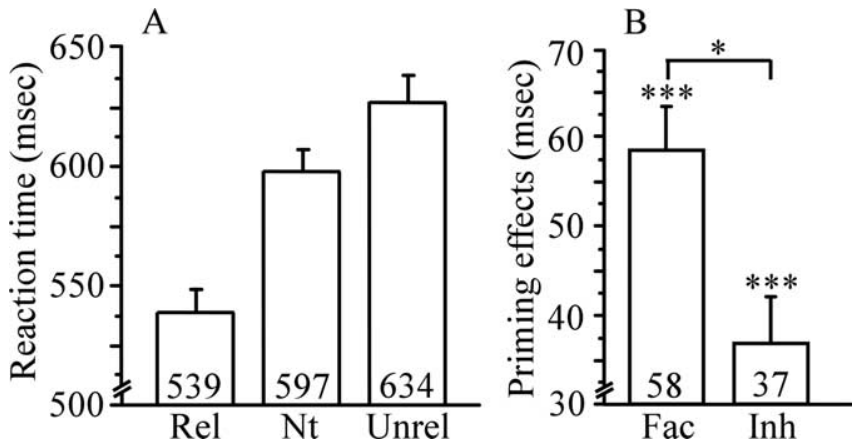

Figure 8. Study 3 RTs and priming effects. $\boldsymbol{A}$, Mean RTs in milliseconds to targets preceded by semantic (Rel), neutral (Nt), and unrelated (Unrel) primes. $\boldsymbol{B}$, Facilitation (Fac) and inhibition (Inh) priming effects. ${ }^{*} p<0.05 ;{ }^{* * *} p<0.001$. Error bars represent SEM. Numbers within bar charts represent exact RTs and priming effects.

gions overlapping those of studies 1 and 2, as well as previous lexical decision studies. Within this network, several regions showed strategic semantic facilitation and inhibition effects (Fig. $9 B$, Table 3 ), including the five regions that showed effects of strategic semantic facilitation in study 1: aLIPC ( $\sim$ BA 47$)$, pLIPC $(\sim$ BA $44 / 45)$, left MTG, and bilateral anterior cingulate $(\sim \mathrm{BA}$ $32 / 24)$. Importantly, however, regions within this network were associated with different components of the strategic semantic priming effect: the aLIPC and MTG showed effects of strategic facilitation, whereas the pLIPC and bilateral anterior cingulate showed effects of strategic inhibition. These results confirm that strategic lexical-semantic processing draws on a distributed frontotemporal network of regions but demonstrate differential sensitivity of regions within this network to lexical-semantic facilitation and inhibition of competing lexical-semantic information.

\section{Discussion}

The present series of studies explored the neural bases of automatic and strategic lexical-semantic processes by examining BOLD decreases associated with primed lexical decision, as a function of SOA and a linguistic relationship between the prime and target. All task conditions resulted in significant behavioral priming. Automatic and strategic semantic behavioral priming were associated with regionally specific BOLD decreases. These neural correlates of automatic and strategic priming were consistent across minor changes in trial structure and reproducible across separate groups of subjects. Importantly, the differing priming decreases observed cannot be attributed to task or stimulus differences because a single lexical decision task was used with stimuli counterbalanced across condition. Results demonstrate differing roles for several regions previously implicated in explicit semantic decision, as a function of automatic and strategic lexical-semantic processes. Below, we describe key findings from the present studies and discuss how these findings inform existing models of the neural organization of lexical-semantics.

Previous functional neuroimaging studies of explicit lexicalsemantic decision have reported activation of a network of frontotemporal brain regions, prominently including the LIPC and left lateral and inferior temporal cortices (Petersen et al., 1988; Buckner et al., 1995; Martin et al., 1995; Binder et al., 1997; Price et al., 1997; Thompson-Schill et al., 1997; Wagner et al., 2001; Gold et al., 2005a). These studies provide an important starting point in defining the neural bases of component lexical-semantic processes, which are likely to involve a subset of regions involved in explicit lexical-semantic decision. Psycholinguistic studies have demonstrated three well established components of the 
lexical-semantic system: automatic activation of semantic representations, strategic retrieval of semantic representations, and inhibition of competitors (Posner and Snyder, 1975; Neely, 1977; Balota et al., 1992). The present research provides strong, reproducible evidence of a neural dissociation between these component processes.

Recently, Wheatley et al. (2005) reported automatic semantic priming in the left mid-FFG. Results from the present research both replicate and extend the findings of Wheatley et al. (2005). Results from study 1 provide a direct demonstration that the mid-FFG shows greater automatic than strategic semantic priming, as can be seen in Figure 5C. In addition, the location of the mid-FFG within the ventral visual stream led us to explore the possibility that the region was involved in automatic orthographic processes that contribute to lexical decision. However, study 2 demonstrated that the left mid-FFG did not show decreased activation when lexical targets were facilitated by orthographic primes. The mid-FFG region showing automatic semantic priming was remarkably consistent across two studies with different participants and slightly different short SOAs (peak $x, y, z$ coordinates: study 1: -40 , $-43,-15$; study 2 : $-42,-44,-15)$ and just lateral to the mid-FFG region reported by Wheatley et al. (2005) (peak: -32, -42, $-12)$.

A role for mid-FFG in semantic processing, broadly conceived, is well established. First, neuropsychological studies have demonstrated a role for a large portion of the inferior temporal cortex (including the mid-FFG) in representing conceptual knowledge (Kertesz et al., 1982; Sharp et al., 2004). Second, intracranial recordings have reported sensitivity to lexical-semantic material in the mid-toanterior FFG (Nobre et al., 1994). The present results, together with those of Wheatley et al. (2005), raise the possibility that the mid-FFG may serve as a store for lexical-semantic information. Other temporal lobe regions are also likely to represent lexical-semantic information. In particular, a body of data suggests a role for left temporal pole in storage of semantic information (Hodges et al., 1992; Mummery et al., 1999a; Gold et al., 2005b), and an effect of automatic semantic priming in the left temporal pole may have been missed because of fMRI signal fallout in this region.

Study 1 also demonstrated greater strategic than automatic semantic priming in four regions: aLIPC $(\sim \mathrm{BA} 47)$, $\mathrm{pLIPC}(\sim \mathrm{BA}$ $44 / 45)$, and bilateral anterior cingulate $(\sim \mathrm{BA} 24 / 32)$. Two distinct cognitive processes contribute to semantic priming at long SOA: facilitation of lexical-semantic retrieval and inhibition of competing lexical-semantic information. Long SOA conditions

C
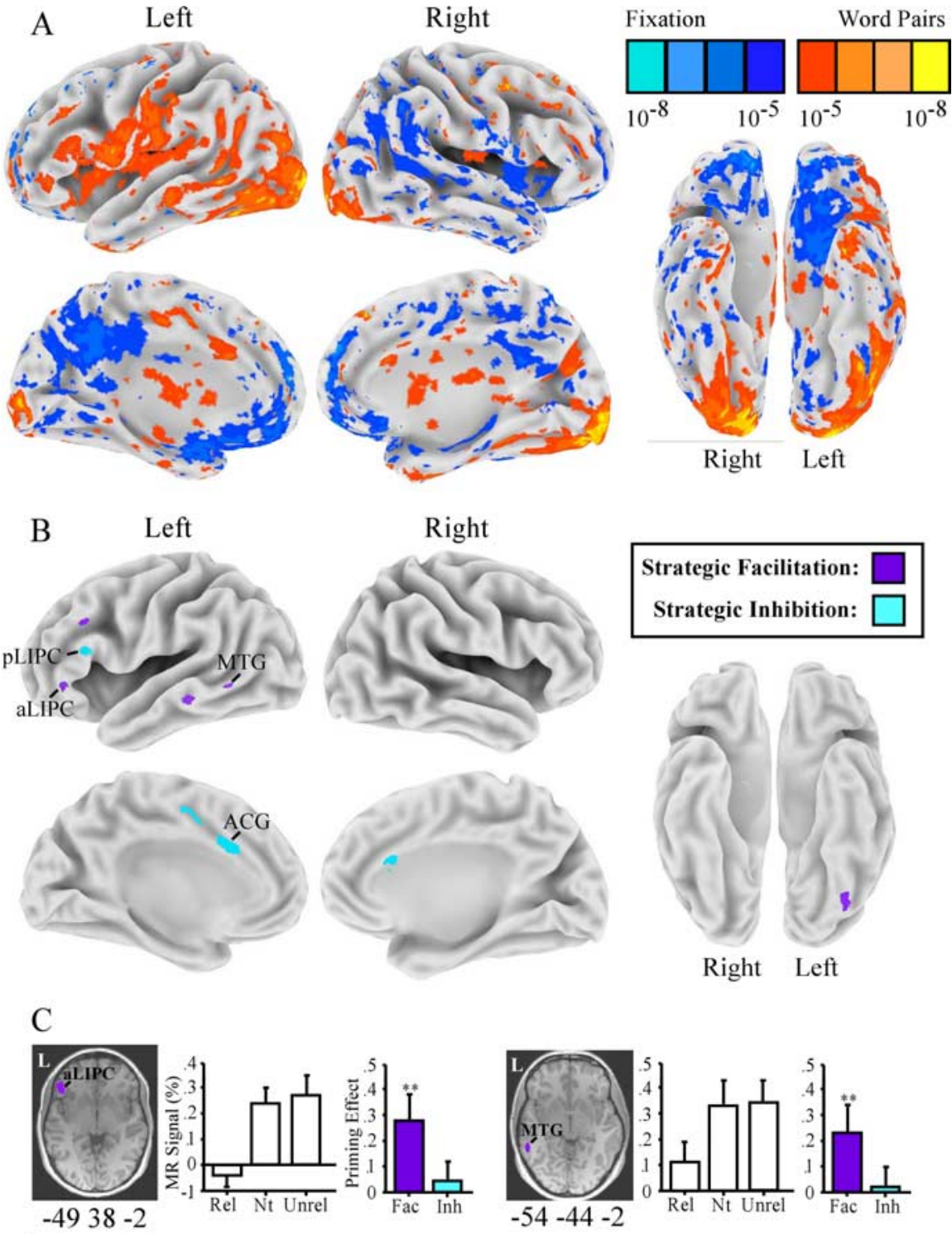

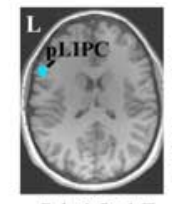

$-541817$
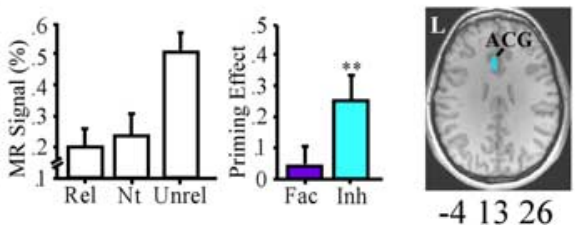

Figure 9. Study 3 MR priming effects. $\boldsymbol{A}$, Whole-brain maps comparing all word conditions with visual fixation. $\boldsymbol{B}$, Maps displaying regions activated by word pairs $(\boldsymbol{A})$ that also show an effect of facilitation (neutral $>$ related) or inhibition (unrelated $>$ neutral). C, Priming effects in two regions showing strategic semantic facilitation (aLIPC and left MTG) and two regions showing strategic semantic inhibition (pLIPC and left anterior cingulate gyrus). Bar charts display mean MR percentage signal change from fixation for the related (Rel), neutral (Nt), and unrelated (Unrel) conditions. Colored bar charts show MR priming effects of facilitation (Fac) and inhibition (Inh). ${ }^{* *} p<0.01$. Error bars represent SEM. ACG, Anterior cingulate gyrus.

encourage an expectancy strategy during lexical decision involving the generation of potential targets semantically related to the prime. This process facilitates recognition of anticipated words (related targets) by reducing demands on lexical search and access but slows recognition of unexpected words (unrelated trials) because time is required to inhibit the anticipated words and shift attention to the presented item (Neely, 1991; Balota et al., 1992).

Study 3 demonstrated a dissociation between the aLIPC and pLIPC in strategic semantic processing. As can be seen in Figure $9 C$, the aLIPC showed similar response during unrelated and 


$\begin{aligned} & \text { Table 3. Peak coordinates (Talairach and Tournoux, 1988) and } \boldsymbol{p} \text { values for brain } \\
& \text { regions that showed an effect of facilitation or inhibition }\end{aligned}$
\begin{tabular}{llll} 
Region & Approximate BA & $x, y, z(\mathrm{~mm})$ & $p$ \\
\hline $\begin{array}{l}\text { Facilitation (neutral }>\text { related) } \\
\text { Left MTG }\end{array}$ & 21 & $-55,-43,-1$ & $<0.01$ \\
Left MTG & $21 / 22$ & $-51,-35,-10$ & $<0.01$ \\
Left middle frontal gyrus & $9 / 8$ & $-43,28,36$ & $<0.01$ \\
aLIPC & 47 & $-46,33,-3$ & $<0.01$ \\
Inhibition (unrelated $>$ neutral) & & & $<0.01$ \\
Left anterior cingulate gyrus & $24 / 32$ & $-6,13,26$ & $<0.01$ \\
Left anterior cingulate gyrus & 24 & $-11,3,37$ & $<0.01$ \\
Right anterior cingulate gyrus & $24 / 32$ & $+4,16,29$ & $<0.01$ \\
pLIPC & $44 / 45$ & $-49,27,24$ & \\
\hline
\end{tabular}

neutral conditions and a decrease in activation during the related condition. A different pattern was found in the pLIPC, which showed a similar response to neutral and related conditions and an increase during the unrelated condition. These different effects were evident in formal voxel-based analyses: the aLIPC showed strategic semantic facilitation or decreased activation on related trials compared with unrelated trials. In contrast, the pLIPC showed strategic semantic inhibition or increased activation on unrelated trials compared with neutral trials. This dissociation provides insight into the debate between two prominent theories of LIPC functioning, which alternatively suggest that the LIPC is specialized for strategic retrieval of lexical-semantic representations from long-term memory (Wagner et al., 2001), or for selecting task-relevant lexical-semantic representations from among competitors (Thompson-Schill et al., 1997). The present results demonstrate a role for the aLIPC in strategic retrieval of lexical-semantic representations and a role for the PLIPC in selecting task-relevant lexical-semantic representations from among competitors.

The present retrieval/selection dissociation within the LIPC was associated with strategic semantic components of visual word recognition but is likely to apply to other strategic verbal processes. For example, Badre et al. (2005) reported that activation in the aLIPC ( $\sim$ BA 47$)$ was sensitive to strategic retrieval demands during explicit semantic decision (manipulated by cuetarget associative strength), whereas activation in the pLIPC ( $\sim$ BA 45$)$ was sensitive to selection demands (manipulated in multiple ways). Dobbins and Wagner (2005) found a similar LIPC dissociation in the domain of memory source recollection, observing aLIPC ( $\sim$ BA 47$)$ activation during strategic retrieval of semantic details and pLIPC ( $\sim$ BA $44 / 45)$ activation under conditions emphasizing selection of relevant from irrelevant information from memory, whether semantic or nonsemantic.

In the present research, the left MTG, like the aLIPC, showed decreased response on trials in which strategic lexical-semantic search and access processes were facilitated by semantic primes (related trials) compared with trials that were not (neutral trials). A coordinated role for the aLIPC and MTG in strategic lexicalsemantics is in keeping with previous findings that both these regions show increased activation during semantic tasks that stress strategic search and retrieval processes compared with tasks with less strategic requirements (Wagner et al., 2001; Gold and Buckner, 2002) and decreased activation when these strategic processes are automated through repeated semantic decision on the same stimuli [semantic repetition priming (Raichle et al., 1994; Gold et al., 2005a)]. Although semantic repetition priming also involves perceptual priming, neither the aLIPC nor MTG shows adaptation associated with perceptual priming (Wagner et al., 2000).

The consistent coactivation of the aLIPC and MTG raises the possibility that activation of one region may obligate activation of the other, as a result of strong functional connectivity. Indeed, correlational analysis has suggested strong functional connectivity between aLIPC and MTG activation patterns (Bokde et al., 2001). However, the present results demonstrate that coactivation of the aLIPC and MTG is not obligated, but rather depends on the degree of strategic requirements involved in semantic processing. Whereas aLIPC semantic priming was restricted to the long SOA condition, MTG semantic priming was evident at both short and long SOA conditions. These data are thus inconsistent with a view of the left MTG as a mere storage system of lexical-semantic information. Rather, our findings suggest that the left MTG may be involved in both storage and strategic retrieval of lexical-semantic information [see Badre et al. (2005) for a similar result using a different manipulation of automatic and strategic semantic processing].

One variable known to influence the degree of strategic semantic processing not explored in the present experiments involves the use of a high proportion of related pairs (Neely, 1991). However, relatedness proportion was not manipulated in the present studies to maintain a single, consistent manipulation of strategic semantic processing (SOA length) across studies. By maintaining an equal proportion of related pairs and introducing a single change, the inclusion of a neutral prime condition, results from study 3 demonstrate that the network of regions showing greater priming at long than short SOA in study 1 were differentially involved in the processes of strategic facilitation and inhibition. Future research will be necessary to determine whether these and/or other regions track with relatedness proportion at long SOA.

Finally, our results add to the growing literature on the use of combining linguistic priming paradigms and rapid event-related designs to examine the neural bases of component linguistic processes. By varying the linguistic relationship between prime and target and/or the SOA, in the context of a common task such as lexical decision or reading, this method provides a powerful approach to identifying brain regions that are sensitive to different components of the lexical-semantic system.

\section{References}

Badre D, Poldrack RA, Paré-Blagoev EJ, Insler RZ, Wagner AD (2005) Dissociable controlled retrieval and generalized selection mechanisms in ventrolateral prefrontal cortex. Neuron 47:907-918.

Balota DA, Black SR, Cheney M (1992) Automatic and attentional priming in young and older adults: reevaluation of the two-process model. J Exp Psychol Hum Percept Perform 18:485-502.

Balota DA, Cortese MI, Watson JM, Spieler DH (1998) Chroriometric studies of word recognition: beyond measures of central tendency. Paper presented at the 39th annual meeting of the Psychonomic Society, p 56, Dallas, TX, November.

Balota DA, Cortese MJ, Hutchison KA, Neely JH, Nelson D, Simpson GB, Treiman R. (2002) The English Lexicon Project: a web-based repository of descriptive and behavioral measures for 40,481 English words and nonwords. http://elexicon.wustl.edu/.

Binder JR, Frost JA, Hammeke TA, Cox RW, Rao SM, Prieto T (1997) Human brain language areas identified by functional magnetic resonance imaging. J Neurosci 17:353-362.

Bokde ALW, Tagamets MA, Friedman RB, Horwitz B (2001) Functional interactions of the inferior frontal cortex during the processing of words and word-like stimuli. Neuron 30:609-617.

Bookheimer S (2002) Functional MRI of language: new approaches to understanding the cortical organization of semantic processing. Annu Rev Neurosci 25:151-188.

Buckner RL, Raichle ME, Petersen SE (1995) Dissociation of human prefrontal cortical areas across different speech production tasks and gender groups. J Neurophysiol 74:2163-2173. 
Burgess C, Livesay K (1998) The effect of corpus size in predicting reaction time in a basic word recognition task: moving on from Kucera and Francis. Behav Res Methods Instrum Comput 30:272-277.

Cohen L, Dehaene S, Naccache L, Lehericy S, Dehaene-Lambertz G, Henaff M, Michel F (2000) The visual word form area: spatial and temporal characterization of an initial stage of reading in normal subjects and posterior split-brain patients. Brain 123:291-307.

Cohen L, Lehericy S, Chochon F, Lemer C, Rivard S, Dehaene S (2002) Language-specific tuning of visual cortex? Functional properties of the visual word form area. Brain 125:1054-1069.

Cohen MS (1997) Parametric analysis of fMRI data using linear systems methods. NeuroImage 6:93-103.

Colombo L (1986) Activation and inhibition with orthographically similar words. J Exp Psychol Hum Percept Perform 12:226-234.

Cox RW (1996) AFNI: software for analysis and visualization of functional magnetic resonance neuroimages. Comput Biomed Res 29:162-173.

Cox RW, Jesmanowicz A (1999) Real-time 3D image registration for functional MRI. Magn Reson Med 42:1014-1018.

Dale AM (1999) Optimal experimental design for event-related fMRI. Hum Brain Mapp 8:109-114.

Damasio AR, Damasio H (1983) The anatomic basis of pure alexia. Neurology 33:1573-1583.

Dejerine J (1892) Contribution à l'étude anatomo-pathologique et clinique des différentes variétés de cécité verbale. Mem Soc Biol 4:61-90.

Devlin JT, Jamison HL, Matthews PM, Gonnerman LM (2004) Morphology and the internal structure of words. Proc Natl Acad Sci USA 101: $14984-14988$.

Dobbins IG, Wagner AD (2005) Domain-general and domain-sensitive prefrontal mechanisms for recollecting events and detecting novelty. Cereb Cortex 15:1768-1778.

Forster KI, Davis C, Schoknecht C, Carter R (1987) Masked priming with graphemically related forms: repetition of partial activation? Q J Exp Psychol 39A:211-251.

Glover GH (1999) Deconvolution of impulse response in event-related BOLD fMRI. NeuroImage 9:416-429.

Gold BT, Buckner RL (2002) Common prefrontal regions co-activate with dissociable posterior regions during strategic semantic and phonological tasks. Neuron 35:803-812.

Gold BT, Balota DA, Kirchhoff BA, Buckner RL (2005a) Common and dissociable activation patterns associated with controlled semantic and phonological processing: evidence from fMRI adaptation. Cereb Cortex 15:1438-1450.

Gold BT, Balota DA, Cortese MJ, Sergent-Marshall SD, Snyder AZ, Salat DH, Fischl B, Dale AM, Morris JC, Buckner RL (2005b) Differing neuropsychological and neuroanatomical correlates of abnormal reading in earlystage semantic dementia and dementia of the Alzheimer type. Neuropsychologia 43:833-846.

Hagoort P (1993) Impairments of lexical-semantic processing in aphasia: evidence from the processing of lexical ambiguities. Brain Lang 45:189-232.

Hinton J, Liversedge SP, Underwood G (1998) Neighborhood effects using a partial priming methodology: guessing or activation? J Exp Psychol Learn Mem Cogn 24:1294-1305.

Hodges JR, Patterson K, Oxbury S, Funnell E (1992) Semantic dementia: progressive fluent aphasia with temporal lobe atrophy. Brain 115:1783-1806.

Inhoff AW, Tousman S (1990) Lexical priming from partial-word previews. J Exp Psychol Learn Mem Cogn 16:825-836.

Jordan TR (1986) Testing the BOSS hypothesis: evidence for positioninsensitive orthographic priming in the lexical decision task. Mem Cogn 14:523-532.

Kertesz A, Sheppard MA, MacKenzie R (1982) Localization in transcortical sensory aphasia. Arch Neurol 39:475-478.

MacLeod CM (1991) Half a century of research on the Stroop effect: an integrative review. Psychol Bull 109:163-203.

Martin A, Haxby JV, Lalonde FM, Wiggs CL, Ungerleider LG (1995) Discrete cortical regions associated with knowledge of color and action. Science 270:102-105.

Mewhort DJK, Beal AL (1977) Mechanisms of word identification. J Exp Psychol Hum Percept Perform 3:629-640.

Milberg W, Blumstein SE, Katz D, Gershberg F, Brown T (1995) Semantic facilitation in aphasia: effects of time and expectancy. J Cog Neurosci 7:33-50.
Milberg WP, Blumstein SE (1981) Lexical decision and aphasia: evidence for semantic processing. Brain Lang 14:371-385.

Mummery CJ, Patterson K, Hodges JR, Price CJ (1998) Functional neuroanatomy of the semantic system: divisible by what? J Cog Neurosci 10:766-777.

Mummery CJ, Patterson K, Wise RJ, Price CJ, Hodges JR (1999a) Disrupted temporal lobe connections in semantic dementia. Brain 122:61-73.

Mummery CJ, Shallice T, Price CJ (1999b) Dual-process model in semantic priming: a functional neuroimaging perspective. NeuroImage 9:516-525.

Moore CJ, Price CJ (1999) Three distinct ventral occipitotemporal regions for reading and object naming. NeuroImage 10:181-192.

Neely JH (1977) Semantic priming and retrieval from lexical memory: roles of inhibitionless spreading activation and limited-capacity attention. J Exp Psychol 106:226-254.

Neely JH (1991) Semantic priming in visual word recognition: a selective review of current theories and findings. In: Basic processes in reading: visual word recognition (Besner D, Humphreys GW, eds), pp 264-336. Hillsdale, NJ: Erlbaum Associates.

Neely JH, Keefe DE, Ross KL (1989) Semantic priming in the lexicaldecision task: roles of prospective prime-generated expectancies and retrospective semantic matching. J Exp Psychol Learn Mem Cogn 15:1003-1019.

Nelson DL, McEvoy CL, Schreiber TA (1998) The University of South Florida word association, rhyme, and word fragment norms. http://w3.usf.edu/FreeAssociation/.

Nobre AC, Allison T, McCarthy G (1994) Word recognition in the human inferior temporal lobe. Nature 372:260-263.

Petersen SE, Fox PT, Posner MI, Mintun M, Raichle M (1988) Positron emission tomographic studies of the cortical anatomy of single-word processing. Nature 331:585-589.

Posner MI, Snyder CRR (1975) Facilitation and inhibition in the processing of signals. In: Attention and performance V (Rabbitt PMA, ed). London: Academic.

Price CJ, Friston KJ (1997) Cognitive conjunction: a new approach to brain activation experiments. NeuroImage 5:261-270.

Price CJ, Moore CJ, Humphreys GW, Wise RJS (1997) Segregating semantic from phonological processes during reading. J Cogn Neurosci 9:727-733.

Raiche ME, Fiez JA, Videen TO, Macleod AMK, Pardo JV, Fox PT, Petersen SE (1994) Practice-related changes in human brain functional anatomy during nonmotor learning. Cereb Cortex 4:8-26.

Rastle K, Davis MH, Marslen-Wilson WD, Tyler LK (2000) Morphological and semantic effects in visual word recognition: a time course study. Lang Cogn Process 15:507-538.

Rissman J, Eliassen JC, Blumstein SE (2003) An event-related fMRI investigation of implicit semantic priming. J Cogn Neurosci 15:1160-1175.

Rossell SL, Price CJ, Nobre AC (2003) The anatomy and time course of semantic priming investigated by fMRI and ERPs. Neuropsychologia 41:550-564.

Rumsey JM, Horwitz B, Donohue BC, Nace K, Maisog JM, Andreason P (1997) Phonological and orthographic components of visual word recognition: a PET-rCBF study. Brain 120:739-759.

Sharp DJ, Scott SK, Wise JS (2004) Retrieving meaning after temporal lobe infarction: the role of the basal language area. Ann Neurol 56:836-846.

Talairach J, Tournoux P (1988) Co-planar stereotaxic atlas of the human brain. Stuttgart: Thieme.

Thompson-Schill SL, D’Esposito M, Aguirre GK, Farah MJ (1997) Role of left inferior prefrontal cortex in retrieval of semantic knowledge: a reevaluation. Proc Natl Acad Sci USA 94:14792-14797.

Van Essen DC, Dickson J, Harwell J, Hanlon D, Anderson CH, Drury HA (2001) An integrated software system for surface-based analyses of cerebral cortex. J Am Med Inform Assoc 41:1359-1378.

Wagner AD, Koutstaal W, Maril A, Schacter DL, Buckner RL (2000) Taskspecific repetition priming in left inferior prefrontal cortex. Cereb Cortex 10:1176-1184.

Wagner AD, Paré-Blagoev EJ, Clark J, Poldrack RA (2001) Recovering meaning: left prefrontal cortex guides strategic semantic retrieval. Neuron 31:329-338.

Wheatley T, Weisberg J, Beauchamp MS, Martin A (2005) Automatic priming of semantically related words reduces activity in the fusiform gyrus. J Cogn Neurosci 17:1871-1885.

Wiggs CL, Martin A (1998) Properties and mechanisms of perceptual priming. Curr Opin Neurobiol 8:227-233. 